\title{
ENSAIO SOBRE O FECHAMENTO \\ PERSPECTIVO COMO PRINCÍPIO \\ ARTÍSTICO NO DESENHO DAS \\ CIDADES
}

\author{
Aline Stefania Zim ${ }^{1}$ \\ alinezim@gmail.com
}

\section{Resumo}

Esse ensaio desenvolve um estudo comparativo sobre as categorias de análise morfológica no estudo da qualidade dos espaços públicos entre dois autores arquitetos e urbanistas, Camillo Sitte e Gordon Cullen. Propõe-se, de início, a comparação entre o conceito de fechamento perspectivo nas praças antigas, em Sitte, e a noção de recinto e delimitação nas sequências visuais, em Cullen. Admitindo que tais categorias são relevantes, investiga-se, a partir delas, quais são os critérios propostos pelos dois autores para a definição dos princípios artísticos que fazem da cidade uma experiência interessante.

Palavras chave: Camillo Sitte, Gordon Cullen, espaço público, percurso, cidade

Em Eudóxia, que se estende para cima e para baixo, com vielas tortuosas, escadas, becos, casebres, conserva-se um tapete no qual se pode contemplar a verdadeira forma da cidade. À primeira vista, nada é tão pouco parecido com Eudóxia quanto o desenho do tapete, ordenado em figuras simétricas que repetem os próprios motivos com linhas retas e circulares, entrelaçado por agulhadas de cores resplandecentes, cujo alternar de tramas pode ser acompanhado ao longo de toda a urdidura. Mas, ao se deter para observá-lo com atenção, percebe-se que cada ponto do tapete corresponde a um ponto da cidade e que todas as coisas contidas na cidade estão compreendidas no desenho, dispostas segundo as suas verdadeiras relações, as quais se evadem aos olhos distraídos pelo

\footnotetext{
${ }^{1}$ Professora na Universidade Católica de Brasília (UCB) Doutoranda pelo Programa da Pesquisa e PósGraduação da Universidade de Brasília (PPG-FAU-UnB).
} 
vaivém, pelos enxames, pela multidão. A confusão de Eudóxia, os zurros dos mulos, as manchas de negro-defumo, os odores de peixe, é tudo o que aparece na perspectiva parcial que se colhe; mas o tapete prova que existe um ponto no qual a cidade mostra as suas verdadeiras proporções, o esquema geométrico implícito nos mínimos detalhes. É fácil perder-se em Eudóxia: mas, quando se olha atentamente para o tapete, reconhece-se o caminho perdido num fio de carmesim ou anil ou vermelho amaranto que após um longo giro faz com que se entre num recinto de cor púrpura que é o verdadeiro ponto de chegada. Cada habitante de Eudóxia compara a ordem imóvel do tapete a uma imagem sua da cidade, uma angústia sua, $e$ todos podem encontrar, escondidas entre os arabescos, uma resposta, a história de suas vidas, as vicissitudes do destino.

CALVINO, Italo. As cidades Invisíveis. São Paulo: Companhia das Letras, 1990, p. 91.

Perder-se numa cidade é talvez o modo mais interessante de conhecê-la. Os percursos, porque dependem da experiência individual, tecem narrativas urbanas subjetivas e, portanto, roteiros originais. Diferente do roteiro turístico, perder-se na cidade, no sentido da deriva ${ }^{2}$, significa menos uma angústia e mais uma entrega. $\mathrm{O}$ percurso espontâneo - mais interessante que as indicações dos mapas turísticos pressupõe que a cidade deva oferecer diversidade. Toda paisagem urbana, nesse sentido, deveria ser interessante como experiência imagética.

As ruas históricas da cidade de Outro Preto oferecem passeios estreitos e ruas sinuosas. Durante uma caminhada, a paisagem ali é uma sequência inesperada de fragmentos de paisagem. A cidade não se revela facilmente ao observador. Apresenta uma geografia rebuscada, de textura específica, que mantém o caminhante atento ao chão.

\footnotetext{
${ }^{2}$ Deriva é o modo de comportamento experimental ligado às condições da sociedade urbana: técnica de passagem apressada por vários ambientes. Mais particularmente, também designa a duração de um exercício contínuo desta experiência (CARERI, Francesco. Walkscapes: o caminhar como prática estética. São Paulo: Ed. Gilli, 2013, p. 90).
} 
Uma certa noite, enquanto a cidade dormia, decidiu-se caminhar pela Ouro Preto histórica de ruas íngremes e sinuosas em busca da paisagem plena - a arquitetura e silêncio. Quando o sono avisou a hora de voltar, nos perdemos. Subindo, o rua íngreme apresentou a fachada lateral da Igreja da Nossa Senhora do Pilar. Já é muito tarde. A passagem lateral é estreita e não permite o afastamento necessário para que a obra se apresente ao observador. Segue-se, então, com atenção ao caminho irregular. A parede lateral é robusta e se estende muito acima do campo de visão, trazendo a angústia de não se compreender a escala do edifício.

Logo na esquina, ao contornar a grande estrutura de pedras, surge a igreja em sua fachada principal como um gigante adormecido. O passeio noturno, inesperadamente, trouxe um dos maiores monumentos da arquitetura barroca brasileira.

A paisagem do caminhante em Ouro Preto é emoldurada por um campo visual que se revela lentamente enquanto arquitetura e monumento, sob diferentes paisagens. As ruas estreitas e íngremes impedem a visão ampla e panorâmica, conduzindo os pedestres e motoristas aos caminhos sinuosos.

A cidade histórica é compreendida por suas frações, seus quadros, e nunca em sua totalidade. A arquitetura, por sua vez, é revelada aos caminhantes a partir dos seus múltiplos roteiros; o lugar é descoberto aos poucos, por fragmentos. Nesse contexto, o casario colonial incorpora-se aos edifícios monumentais, resultando numa composição arquitetônica que respeita a escala do lugar.

Essa lembrança causa certo encanto e uma reflexão: talvez se tenha experimentado uma sequência das visuais descritas por Camillo Sitte $^{3}$ e desenhadas por Gordon Cullen ${ }^{4}$. De qualquer modo, propõe-se aqui o olhar mais atento sobre os princípios que fazem do espaço urbano uma experiência interessante.

\footnotetext{
${ }^{3}$ Camillo Sitte (Viena, 17 de abril de 1843 - Viena, 16 de novembro de 1903) foi um arquiteto e historiador da arte austríaco, diretor da Escola Imperial e Real de Artes Industriais de Viena.

Foi o autor do estudo urbanístico: Construção das Cidades Segundo seus Princípios Artísticos ("Der Städtebau nach seinen künstlerischen Grundsätzen"). Onde, através de uma análise das cidades na história, Sitte propõe reavaliar a cidade através de seus espaços existentes, principalmente suas praças (disponível em http://pt.cyclopaedia.net/wiki/Camillo-sitte).

${ }^{4}$ GORDON CULLEN nasceu em 1914 e faleceu em 1994. Trabalhou em duas empresas de arquitectura, em Londres. Foi ilustrador e director artístico de exposições na Grã-Bretanha e nas Índias Ocidentais, antes de se tornar subchefe de redacção da revista The Architectural Review, logo após a Segunda Guerra Mundial. Os seus desenhos e artigos acerca de projectos urbanos atraíram nesse período largo interesse, quer pelos ideais quer pelo estilo de apresentação. Na prática, desde 1956, actuou como consultor paisagista junto de numerosas instituições britânicas, assim como da Fundação Ford relativamente a projectos urbanos em Nova Delhi e Calcutá. Foi membro honorário do Real Instituto dos Arquitectos Britânicos a partir de 1970 (disponível em http://www.edicoes70.pt/site/node/3?aut id=423).
} 
Alguns autores estudam, a partir das cidades antigas, os elementos que trazem qualidade espacial ao ambiente urbano, considerando categorias de análise morfológica e tipológica e categorias estéticas. Nesse sentido, o urbanista Camillo Sitte, em $A$ construção das cidades segundo seus princípios artísticos, texto publicado em 1889, vivencia as grandes mudanças nas cidades modernas no século XIX e início do século XX e compõe uma crítica sobre o planejamento urbano modernista, defendendo a preservação dos centros históricos urbanos e os princípios antigos na concepção dos espaços públicos.

Para esse autor, as cidades deveriam ter uma formação espontânea, já que os princípios do planejamento urbano funcionalista são, por natureza, artificiais e utópicos ${ }^{5}$. Nesse sentido, Sitte concentra seu estudo nas praças das cidades antigas medievais, principalmente a partir da observação das perspectivas visuais urbanas. $\mathrm{O}$ autor enfatiza que os espaços públicos deveriam configurar recintos agradáveis e proporcionais ao contexto arquitetônico, além de representar a comunidade envolvida e o que é lhe significativo historicamente - ou seja, o que se deve ou não preservar.

Muitos autores entendem que a predileção de Sitte pelo medieval, assim como seu amor pelo pinturesco ${ }^{6}$, parecem indissociáveis da leitura que faz das qualidades artísticas das cidades antigas quando observa as perspectivas visuais ${ }^{7}$.

O que Sitte defende como pinturesco significa mais uma preferência estética e menos a nostalgia à arquitetura e arte medievais, renascentistas ou barrocas. Essa preferência refere-se mais a princípios estéticos que valorizam a paisagem natural e um traçado urbano orgânico, em contraste a uma linguagem condicionada à régua e ao compasso no desenho das cidades modernistas - onde a forma é resolvida na prancheta, pelo método da planificação gráfica.

\footnotetext{
${ }^{5}$ SITTE, Camillo. A Construção das Cidades segundo seus princípios artísticos. São Paulo: Ática, 1992, p. 197.

${ }^{6} \mathrm{O}$ vocábulo pitoresco ou pintoresco, usual na linguagem cotidiana em inúmeras acepções tomadas por analogia de seu sentido etimológico - pitoresco, no italiano, deriva de pittura, significando "próprio para ser pintado" -, está vinculado a um conceito que, a despeito da aparente superficialidade, acarretou profundas transformações no pensamento estético ocidental. A crítica à rigidez geométrica clássica (simetria, axialidade, comodulação), ao ideal de imitação dos antigos (mimesis), a busca de coerência formal entre as qualidades materiais e as técnicas construtivas, de adequação às exigências utilitárias, em suma, a concepção da arte como expressão autêntica, livre do artificialismo das convenções estilísticas, liga-se de modo inequívoco à assunção do pitoresco como valor artístico precípuo da arquitetura.

${ }^{7}$ SALGADO, Ivone. Uma leitura sobre a concepcạa estética de Camillo Sitte: A construcạao do espaço perspéctico. Pontifícia Universidade Católica de Campinas; São Paulo; Brasi. Disponível em: http://www.mackenzie.br/dhtm/seer/index.php/cpgau.
} 
Um dos critérios mais relevantes no texto de Sitte sobre a arte de construir espaços públicos é o do fechamento visual perspectivo. Espaços urbanos como o fórum romano, a praça medieval e as praças do século XVI foram construídos como lugares perspectivamente fechados, revelando princípios artísticos em sua concepção.

As cidades antigas preservadas, segundo o autor, conservaram naturalmente uma tipologia urbana diversificada. Observa-se, por exemplo, a sinuosidade das ruas. Além de dar continuidade às condicionantes físicas e históricas do local, como a adaptação às condições do terreno, a preservação de uma edificação histórica ou de um curso d'água (SITTE, 1992, p. 187), as ruas sinuosas oferecem ao olhar do transeunte horizontes diferentes e, por consequência, percursos mais interessantes. Essas visuais são marcadas mais pelo fechamento, por serem fragmentos urbanos observados na escala humana, do que pela abertura visual, que torna a paisagem revelada e repetitiva, típico nas cidades modernistas.

A falta de fechamento lateral nas ruas das praças, por exemplo, provoca uma abertura visual que revela tudo ao mesmo tempo, ou seja, é monótona enquanto desvelamento da cidade. Segundo o autor,

O fechamento do espaço e dos efeitos de visão era a base de todas as disposições nas cidades antigas, $e$ derivou da evolução histórica de uma rua que era sem interrupções quando de sua formação, como ainda hoje ocorre nas aldeias. A disposição moderna segue o caminho contrário, dividindo tudo em blocos isolados: blocos de casas, blocos de praças, blocos de jardins, tudo circunscrito ao traçado das ruas.(SITTE, 1992, $p$. 187)

A relação entre os espaços construídos e não construídos, segundo o autor, deve ser inversa - sem que seja necessário ignorar os princípios higienistas - para que se tenha o enquadramento do vazio, trazendo espaços agradáveis de proteção e abrigo ao conjunto urbano.

Segundo Sitte, "hoje, quase ninguém mais se ocupa da construção urbana enquanto obra de arte, mas apenas enquanto um problema técnico" (SITTE, 1992, p. 94). Nesse contexto, cita também uma publicação do Fígaro parisiense em 1874 sobre o relato de viagem do marechal Mac-Mahon: 
Rennes não é particularmente antipática ao marechal, mas de qualquer modo, esta cidade não é capaz de entusiasmo algum. Reparei que isso acontece com todas as cidades dispostas em linhas retas linha reta não permite a ocorrência de agitações. Assim, em 1870 se observou que as cidades construídas com absoluta regularidade podiam ser tomadas por três únicos soldados, enquanto as cidades antigas, repletas de ângulos e curvas, estavam sempre prontas a se defender até o fim.(SITTE, 1992, p. 95)

A crítica de Sitte quanto ao planejamento urbano moderno é de que a regularização do traçado das ruas tem um objetivo puramente funcionalista. As malhas ortogonais retangulares, radiais ou triangulares só podem ser apreendidas pelos sentidos em sua totalidade na planta técnica. Formas orgânicas ou angulosas, dentro desse contexto, são dificilmente apreensíveis na escala humana, pois nossa percepção tem uma experiência perspectiva basicamente ortogonal, de um ou dois ponto de fuga.

As formas e malhas regulares exerceram grande influência ao longo da história da arquitetura e urbanismo. Desde a Antiguidade, o traçado ortogonal na construção civil se consolidou em todas as civilizações. Além disso, a perspectiva linear tornou-se um método projetual a partir do renascimento, priorizando as formas ortogonais no desenho das cidades.

Dentro dos princípios do traçado urbano regular - principalmente no urbanismo modernista, Sitte critica a regra de que todas as ruas devem cruzar-se perpendicularmente, numa continuidade visual que aponta para fora da cidade. Afirma que todo o prazer local é comprometido pela necessidade constante de se abandonar o passeio para atravessar as ruas. O que falta ali, segundo ele, é a proteção natural de uma série contínua de fachadas ${ }^{8}$, como no antigo traçado medieval onde

A contenção das cidades em seu cinturão de muralhas e o pequeno número de suas vias de comunicação eram muito favoráveis à estética da rua. A rua ideal deve formar um todo fechado! Nela, quanto mais limitadas

\footnotetext{
${ }^{8}$ Ibidem, p. 104.
} 
forem as impressões, mais o quadro será perfeito. Sentimo-nos à vontade em um espaço onde o olhar não pode perder-se no infinito.(SITTE, 1992, p. 104)

Criticando tal abertura visual, presente nas cidades de traçado regular que usam dos cruzamentos infinitos ortogonais para organizar o trânsito, Sitte novamente traz a comparação com as cidades antigas:

O que temos é o máximo de abertura da visão sobre as linhas de tráfego, algo que os antigos evitavam com todos os artifícios. O ponto de confluência do tráfego é também o ponto de confluência de todas as linhas de visão. Ao contornarmos a praça temos sempre a mesma imagem perante os olhos, de maneira que nunca sabemos ao certo onde estamos. (SITTE, 1992, p.105)

Os turistas facilmente se perdem nesse contexto, pois a paisagem, ao longo do percurso, não se modifica o bastante para dispor de referenciais urbanos. A variedade tipológica, ao contrário, oferece panoramas que, envolvidos por recursos como o contraste, a hierarquia ou o fechamento visual, fazem da cidade um percurso mais rico e legível, porque permeado de referências urbanas.

O desenho urbano funcionalista, para o autor, produz cidades artificiais e monótonas enquanto paisagem. Tais soluções, por serem inapreensíveis enquanto um todo, "não apresentam nenhum interesse artístico. Artisticamente relevante só é aquilo que pode ser visto como um todo, ser apreendido em sua totalidade - portanto, uma única rua, uma única praça”. (SITTE, 1992, p.100)

As construções antigas, ao contrário das cidades modernas, visavam provocar um efeito e não corresponder a uma planta. Esse é o indicativo, segundo Sitte, de um bom desenho urbano, pois só tem relevância artística o conjunto que pode ser visto como um todo e ser apreendido enquanto local. (SITTE, 1992, p.101)

Algumas categorias de análise do espaço urbano para Cullen são pertinentes aqui, como a visão serial, recinto, delimitação, ponto focal, escala, contraste, expectativa e relacionamento. A princípio, é relevante explorarmos a visão serial proposta por Cullen como uma categoria de análise morfológica urbana. 
A visão serial é composta por uma sucessão de pontos de vistas, representados por desenhos ou fotografias, que ilustram fragmentos de um percurso, muitas vezes indicado num mapa esquemático do lugar. Segundo a descrição do autor,

A progressão uniforme do caminhante vai sendo pontuada por uma sério de contrastes súbitos que têm grande impacto visual e dão vida ao percurso (como a leve cotovelada que se dá ao vizinho que está prestes a dormir na missa). (...) Repara-se que os mínimos desvios ao alinhamento, as pequenas variações nas saliências e reentrâncias, em planta, têm um efeito dramático não proporcional na terceira dimensão. (GORDON, 2009, p.19)

Aqui o autor se aproxima da descrição de Sitte sobre o traçado pinturesco que oferece ao percurso uma paisagem urbana diversificada e interessante. A partir das ilustrações, Cullen representa os quadros enquanto percepção fragmentada do percurso do caminhante; este explora a cidade e é acometido por uma sucessão de interessantes efeitos perspectivos, resultantes do conjunto formado por espaços construídos e espaços não construídos.

A partir da categoria da visão serial, propõe-se uma comparação entre o conceito de fechamento perspectivo nas praças públicas de Sitte e o conceito de recinto e delimitação, categorias propostas por Cullen. Segundo esse autor,

$O$ recinto é uma síntese da polaridade entre pés e pneus, isto é, entre a circulação de pessoas e a de veículos. É a unidade base duma certa morfologia urbana. Fora dele, o ruído e o ritmo apressado da comunicação impessoal, vai-vem que não se sabe para onde vai nem donde vem: no interior, o sossego e a tranquilidade de sentir que o largo, a praceta, ou o pátio têm escala humana. O recinto é o objectivo da circulação, o local para onde o tráfego nos conduz. Sem ele, o tráfego tornar-se-ia absurdo. (GORDON, 2009, p.27) 
A categoria de recinto aqui é essencialmente morfológica. Apesar dos espaços fins serem ocupados por pessoas e portanto dependerem de suas ações, Cullen os analisa em seu aspecto essencialmente formal. Para tanto, ele traz a noção espacial do Aqui, ou seja, a identificação com um certo lugar, como sensação oposta do Além, enquanto espaço externo ao Aqui, ou melhor, além do recinto. $\mathrm{Na}$ relação entre as duas qualidades residiria um certo dramatismo entre as relações espaciais urbanas.(GORDON, 2009, p.35)

Para tanto, o trajeto deverá apresentar uma diversidade arquitetônica interessante para que tal efeito de dramatização ocorra, alternando espaços abertos e fechados. Aqui se faz relevante o estudo dos elementos que provocam o fechamento perspectivo, ou seja, que delimitam o quadro da paisagem. Uma visual excessivamente aberta revelaria imediatamente todo o percurso, reduzindo ou extinguindo o efeito dramático.

Essa noção de delimitação ou espaço delimitado distingue-se da noção de recinto. Segundo Cullen

O espaço delimitado é consequência de irregularidades ou assimetrias de traçado, em que o trajecto do ponto de partida ao ponto de chegada não é automaticamente oferecido ao olhar, como na malha ortogonal. Estas irregularidades dividem o percurso numa sequência de propostas visuais reconhecíveis, cada uma efetivamente, e por vezes surpreendentemente, articulada à seguinte, de modo que o percurso a pé é enriquecido através das subdivisões criadas, que são à escala humana; da proposta de incidentes; do sentido do desenrolar ou da revelação, e da identificação.( SITTE, 1992, p.108)

Enquanto o recinto configura um ponto de partida ou de chegada, a delimitação corresponde a um percurso. O recinto enquanto espaço de caráter íntimo, estático e virado para si próprio, convidará o caminhante ao descanso, à contemplação, como as praças, pracetas e largos. Já a noção de delimitação traz a cidade linear enquanto percurso articulado aos recintos urbanos. 
O fechamento perspectivo é descrito em Sitte a partir da irregularidade nas plantas esquemáticas das frações urbanas, as quais geram paisagens mais interessantes que a visão aberta num traçado funcionalista ortogonal, por exemplo. Tal ideia mostrase de modo semelhante na noção de visão serial em Cullen.

Para ambos a composição urbana entre edifícios e superfícies é essencial na configuração de um espaço perspectivo fechado. Tal efeito se dá mais a partir do percurso pelo conjunto edificado e menos pelo espaço vazio residual, produto de um desenho urbano que não consegue articular as suas diferentes escalas.

Segundo Cullen, os conjuntos de edifícios são mais interessantes que edifícios isolados. Enquanto composição de cheios e vazios, o conjunto edificado proporciona percursos mais complexos e interessantes. A maneira com que o transeunte se relaciona com essa superfície do espaço vazio delimitado é que definirá o quanto esse trajeto e as visuais serão interessantes.

É importante, nesse sentido, que o desenho urbano tenha a sua inspiração nos elementos relacionados à apropriação da cidade, principalmente aos caminhos percorridos e roteiros dos transeuntes. Essa preocupação é essencialmente plástica, por admitir que existe uma arte da paisagem construída (SITTE, 1992, p.195); e relacional, por explorar na cidade a justaposição entre as diversas escalas - entendendo, por exemplo, que a escala humana e a monumental podem conviver numa situação de mútua valorização (SITTE, 1992, p.81). Nesse sentido, Cullen afirma que

Em relação a um grupo de edifícios, se um deles não se enquadra, pela sua função, no conjunto: o caso de um banco, um templo ou uma igreja, no meio de casas de habitação por exemplo. Se apenas surgir diante do observador, por hipótese, o templo, todos os aspectos relativos à sua dimensão, complexidade, cor e outros serão bem evidentes. Se, pelo contrário, este se encontrar entre o casario, o contraste entre as duas escalas fará com que pareça mais real e maior: em lugar de um templo grande aparecerá como um templo monumental. A diferença de significado entre grandeza e monumentalidade dá-nos a medida desta correlação. (SITTE, 1992, p.09) 
$\mathrm{O}$ contraste entre as diferentes escalas na paisagem faz com que o conjunto entre a escala monumental e a ordinária ofereça a aproximação do monumento ao passeio comum, dando uma certa continuidade à escala humana. Aqui pode-se identificar a categoria da delimitação, enquanto referencial urbano, e do recinto, se houver uma praça ou largo diante do monumento.

De modo semelhante, Sitte acredita que a justaposição das escalas urbanas humana e monumental, por exemplo - é um fator de qualidade espacial urbana. $\mathrm{O}$ efeito atrativo visual de um monumento, segundo o autor, seria ampliado se ele estivesse inserido ou próximo a um conjunto de edifícios existentes e não dele isolado. Pelo contraste entre as escalas, o monumento pareceria maior, relativamente.

Sobre o isolamento dos monumentos, geralmente locados no centro das praças das cidades modernas, Sitte defende o espaço central vazio, garantindo-se a liberdade das linhas de fluxos e a liberdade das linhas de visão, considerando-as um importante efeito visual artístico. Nesse sentido, o autor diz que

A regra do centro livre não é válida apenas para chafarizes e monumentos, mas também para edifícios, $e$ sobretudo igrejas, que hoje, quase sem exceções, também são colocadas no centro das praças, em contraste radical ao costume antigo. $O$ exame cuidadoso destas relações nos ensina que antigamente, sobretudo na Itália, as igrejas não eram construídas isoladas - suas praças mais interessantes resultaram da construção da igreja encostada em outras estruturas ou encaixada nelas, seja em um, dois, ou mesmo três lados, conforme veremos adiante.(SITTE, 1992, p.39)

Acredita-se que o caminhante se sentirá mais confortável ao acessar um templo integrado à malha urbana ordinária do que um templo isolado num espaço vazio, mergulhado em sua própria escala de contemplação. Ele perceberá o conjunto como um espaço urbano contínuo, mais ainda se houver acessibilidade adequada.

Tais espaços, que são formados por recintos - praças ou pracetas - ou largos, trazem o distanciamento perspectivo necessário para a contemplação ou elaboração de visuais na escala monumental, pois alternam situações de maior e menor abertura visual, num roteiro que representa alguns dos princípios artísticos das antigas cidades. 
A partir dessa análise, a condição artística pode ser o entendimento de que o percurso e o recinto enquanto desenho urbano não devem ser concebidos apenas na dimensão funcional, onde o monumento se revela em sua totalidade, mas também oferecer efeitos surpreendentes. Segundo Cullen,

Se os nossos centros urbanos fossem desenhados sob a ótica da pessoa que se desloca (quer à pé, quer de automóvel) a cidade passará a ser uma experiência eminentemente plástica, percurso através de zonas de compressão e de vazio, contraste entre espaços amplos e espaços delimitados, alternância de situações de tensão e momentos de tranquilidade.(GORDON, 2009, p.12)

O fechamento perspectivo depende, nesse sentido, da relação do conjunto edificado com o espaço vazio, dentro de um intervalo de espaço e tempo - o tempo de duração do percurso no espaço da fração urbana. Segundo Sitte, a cidade como lugar não é um espaço liso e homogêneo, mas é diversificada. Ela "é vista por aquele que transita por suas ruas, atravessa seus territórios, repousa em suas praças, realizando percursos variados por esse espaço que tem algo de labirinto". A cidade é apreendida pelo cidadão comum, o homem da rua, que não a vê em sua totalidade, como na perspectiva de pássaro ou nas planificações, mas a percebe a partir do fragmento, como pedaços recortados de um tecido urbano. (SITTE, 1992, p.05)

Para ilustrar suas categorias, Cullen se utiliza de desenhos e fotografias articuladas às respectivas plantas esquemáticas, seriadas ou não, de exemplares variados. Tais imagens se referem mais às categorias estéticas e menos ao contexto histórico e cultural. Basta observar que o autor nem sempre cita a procedência das ilustrações: mais importante para ele é o efeito plástico entre os espaços cheios e vazios, dentro da variação tipológica arquitetônica, enquanto possibilidades de vivências urbanas.

Já Sitte declara uma preferência aos espaços públicos clássicos, medievais e barrocos - sagrados como os templos e igrejas, ou profanos, como as praças de mercados - que apresentam temas definidos ou redefinidos pelo planejamento ao longo da história da arquitetura e urbanismo. Defendendo os princípios artísticos na 
concepção, formação e preservação das cidades, o autor escolhe como exemplos de análise comparativa os espaços vazios circundantes aos edifícios públicos, às igrejas e aos templos, denominando-os as praças, fóruns e ágoras.

Talvez pela recorrência histórica, Sitte escolheu os exemplos das praças em torno das igrejas medievais, renascentistas e barrocas italianas e do norte da Europa. O tema religioso pode ser justificado pela tradição cristã ter explorado as técnicas construtivas e artísticas, muitas vezes esgotando-as na representação da arte, arquitetura e urbanismo da sua época. Além de espaços de encontro, as praças acentuam as igrejas, prédios públicos, estátuas e chafarizes, porque tal espaço vazio permite a pausa da perspectiva cujo ponto focal são os monumentos e o objetivo é a contemplação.

Os espaços públicos, nesse contexto, são geralmente antigas propriedades das instituições dominantes e, seja por tradição, valor artístico ou poder, as formações originais foram, em sua maioria, preservadas ao longo do tempo. Essa condição representa a base fundamental do traçado urbano das antigas cidades europeias e das colônias que mantiveram as tradições cristãs, sendo determinantes no planejamento urbano em áreas de patrimônio.

Faz-se relevante um estudo comparativo mais denso entre as categorias de Cullen e os a descrição analítica de Sitte. Considerando que Sitte utiliza mais da descrição comparativa dos monumentos e plantas esquemáticas, há uma certa dificuldade do leitor em entender o que significam os critérios de qualidade projetual defendidos. A hipótese é de que Cullen, a partir das suas categorias ricamente ilustradas por desenhos e fotografias, consegue representar melhor o fechamento das visuais e a irregularidade descritas por Sitte.

Não é propriamente o formato da praça que traz o efeito desejado, mas sim o resultado da volumetria circundante resultado de um processo histórico que vai trazer a irregularidade e a diversidade na tipologia arquitetônica, como formação natural ao longo do tempo. É o conjunto da volumetria em relação ao espaço vazio, numa determinada duração de tempo do percurso, que vai fazer com que a praça tenha o efeito defendido como artístico e não propriamente o desenho dela em planta.

O efeito do fechamento e da visão serial para um caminhante que percorre determinada fração urbana depende de uma duração, ou seja, de um percurso subjetivo, entendido mais como um filme e menos como uma imagem estática como as planificações, desenhos e fotografias. Os dispositivos móveis de filmagem e simulação tridimensional, enquanto captadores da fração de espaço e tempo do percurso, poderiam 
ocupar tal lacuna dentro categorias de análise urbana. Mesmo assim, a percepção e vivência no espaço real supera todo método imagético ou gráfico no estudo das cidades.

A planta de uma praça irregular pode ser analisada sob diversas categorias, mas quanto à complexidade da sua situação no espaço urbano real, esse método, que se dá a partir da planificação ou do enquadramento, é reducionista. Outras categorias, portanto, devem ser investigadas para a análise urbana, contextualizando as situações no tempo e espaço, pois a irregularidade do desenho urbano, defendida por Sitte e Cullen, é o resultado das decisões históricas sobre o que é preservado e o que é destruído - sobre a relação do novo com o existente.

\section{REFERÊNCIAS BIBLIOGRÁFCAS}

CALVINO, Italo. As cidades Invisíveis. São Paulo: Companhia das Letras, 1990, p. 91. CARERI, Francesco. Walkscapes: o caminhar como prática estética. São Paulo: Ed. Gilli, 2013.

CERTEAU, Michel de. A invenção do Cotidiano. Petrópolis: Editora Vozes, 1998.

CULLEN, Gordon. Paisagem Urbana. Lisboa: Edições 70, LDA, 2009.

JACOBS, Jane. Morte e Vida de Grandes Cidades. São Paulo: Martins Fontes, 2011.

LYNCH, Kevin. A Imagem da Cidade. São Paulo: Martins Fontes, 2011.

SALGADO, Ivone. Uma leitura sobre a concepção estética de Camillo Sitte: A construção do espaço perspéctico. Pontifícia Universidade Católica de Campinas; São Paulo; Brasi. Disponível em: http://www.mackenzie.br/dhtm/seer/index.php/cpgau. ISSN $1809-4120$

SITTE, Camillo. A Construção das Cidades segundo seus princípios artísticos. São Paulo: Ática, 1992.

\section{Sites Pesquisados:}

http://www.edicoes70.pt/site/node/3?aut id=423

http://pt.cyclopaedia.net/wiki/Camillo-sitte 